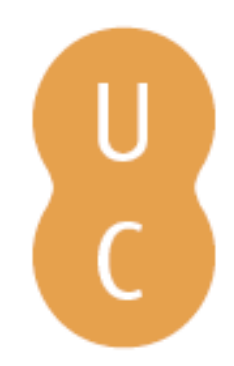

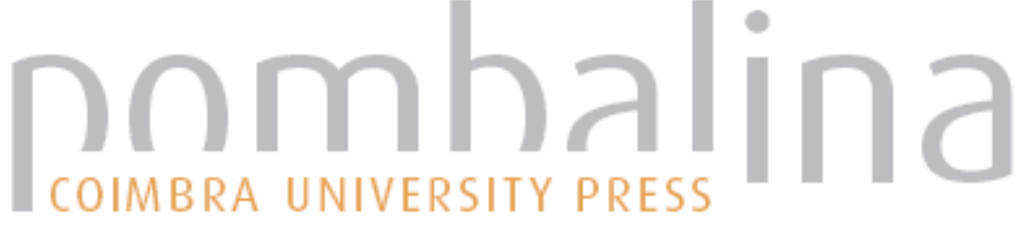

\section{Introdução e apresentação}
Autor(es):
Paes, Maria Tereza Duarte
Publicado por: Imprensa da Universidade de Coimbra
URL persistente:
URI:http://hdl.handle.net/10316.2/43431
DOI:
DOI:https://doi.org/10.14195/978-989-26-1475-5_2

Accessed : $\quad$ 26-Apr-2023 15:21:59

A navegação consulta e descarregamento dos títulos inseridos nas Bibliotecas Digitais UC Digitalis, UC Pombalina e UC Impactum, pressupõem a aceitação plena e sem reservas dos Termos e Condições de Uso destas Bibliotecas Digitais, disponíveis em https://digitalis.uc.pt/pt-pt/termos.

Conforme exposto nos referidos Termos e Condições de Uso, o descarregamento de títulos de acesso restrito requer uma licença válida de autorização devendo o utilizador aceder ao(s) documento(s) a partir de um endereço de IP da instituição detentora da supramencionada licença.

Ao utilizador é apenas permitido o descarregamento para uso pessoal, pelo que o emprego do(s) título(s) descarregado(s) para outro fim, designadamente comercial, carece de autorização do respetivo autor ou editor da obra.

Na medida em que todas as obras da UC Digitalis se encontram protegidas pelo Código do Direito de Autor e Direitos Conexos e demais legislação aplicável, toda a cópia, parcial ou total, deste documento, nos casos em que é legalmente admitida, deverá conter ou fazer-se acompanhar por este aviso.

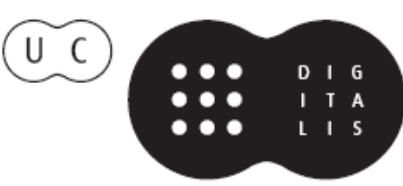


Considerando a importante questão contemporânea que convoca olhares interdisciplinares para compreender as relações entre o patrimônio cultural, o turismo e o planejamento territorial, este livro traz importantes contribuições para o público preocupado com o processo de institucionalização do patrimônio, com a sua associação à valorização turística dos lugares, e com as políticas públicas para o planejamento territorial. Os artigos aqui apresentados são resultado da parceria de projetos, intercâmbios e pesquisas comuns entre o Programa de Pós-Graduação em Geografia da Universidade do Estado do Rio de Janeiro (UERJ) e o Grupo de Pesquisa (Diretório CNPq) Geografia, Turismo e Território (Laboratório de Geografia Urbana) do Departamento de Geografia/Instituto de Geociências, da Universidade Estadual de Campinas (UNICAMP), São Paulo. Todos os autores aqui presentes participaram como palestrantes de nosso IV Seminário de Geografia, Turismo e Patrimônio Cultural, realizado em novembro de 2012 na Universidade do Estado do Rio de Janeiro (PPGG/UERJ), e produziram as suas contribuições a partir do desenvolvimento da temática relativa à Geografia, à Sociologia, à História e à Arquitetura, na interface entre o Turismo e o Patrimônio Cultural.

Tomando como referência o fato de já termos publicado um primeiro livro, Geografia, Turismo e Patrimônio Cultural (Paes \& Oliveira, 2009), a partir das investigações e Seminários organizados junto ao Grupo de Pesquisa, cabe aqui tecer algumas considerações sobre a trajetória das pesquisas nesta área.

Embora a abordagem geográfica do turismo tenha tomado um importante lugar entre as reflexões científicas desde os anos 1980 e, mais intensamente, a partir dos anos 1990, as investigações sobre o patrimônio cultural são bem 
mais recentes. No que concerne às ciências sociais ou aplicadas, o patrimônio cultural manteve-se objeto de investigação de outros campos, tais como da história, da arquitetura e da arqueologia. A Geografia tomou mais tardiamente o patrimônio cultural como objeto de pesquisa, o que não invalidou a sua importante contribuição contemporânea (Paes, 2015, p. 54). E este fato não foi restrito à Geografia brasileira. Na França, território consagrado ao patrimônio cultural, a abordagem geográfica deste também só se inicia, praticamente, nos anos 2000, com uma rica e particular contribuição disciplinar que renovou as abordagens ao colocar no centro do debate a sua dimensão espacial, política, e como objeto dos interesses do presente, e não apenas da preservação do passado. Os conflitos de interesses de usos nas disputas territoriais, quer sejam áreas urbanas ou naturais; a fetichização das paisagens refuncionalizadas; as lógicas contraditórias entre um patrimônio que se quer globalizado às custas do patrimônio vivido por suas populações na escala local; e também a produção simbólica, tomada como legitimação de grupos sociais em um campo de conflito e dominação de ideologias na apropriação territorial ganharam luz nas investigações geográficas.

A dimensão cultural na Geografia clássica havia sido tratada, majoritariamente, pelo método positivista, o que restringiu as suas abordagens às metodologias objetivistas, classificatórias e descritivas das paisagens e bens culturais. Mesmo as abordagens iniciais da Geografia Crítica Marxista não permitiram encontrar na cultura um objeto de investigação que pudesse dar conta - como chave aproximativa da interpretação -, da totalidade social. Apenas recentemente o campo da cultura ganhou novamente prestígio nas reflexões geográficas, a partir de uma renovação de olhares e métodos que ampliaram a sua contribuição.

Importante frisar que tomar a dimensão cultural como recorte impõe algumas explicações de método. A primeira é que consideramos a cultura como constituinte das outras dimensões da vida, tais como a economia, a política, a social, a espacial, entre outras. Desde o início do processo de patrimonialização, geral e no Brasil, a dimensão cultural é utilizada como legitimação de interesses políticos, territoriais e, hoje, mais do que nunca, econômicos. A força das representações culturais - que dão significado, atribuem valores e ritualizam ações - coloca-se como ferramenta estratégica nas disputas de poder em várias dimensões da vida.

E além de debruçar o seu olhar sobre o patrimônio cultural, a Geografia tem apresentado importantes contribuições à associação inevitável e con- 
troversa entre o turismo e o patrimônio cultural. Na França, autores como Guy Di Méo (1994), Olivier Lazzarotti (2011; 2000), Maria Gravari-Barbas (2014), Vincent Veschambre (2007), Anne Hertzog (2011), entre outros, são referências importantes neste debate.

A complexidade do cruzamento entre abordagens culturais, sociais, políticas, ambientais, econômicas; o diálogo interdisciplinar imprescindível; o conhecimento institucional dos processos de patrimonialização; e a dimensão espacial como eixo central em nossas análises, vieram edificando uma nova reflexão sobre patrimônio cultural, resgatando as heranças do passado em seus usos no presente - tema quase ausente, até então, em outras áreas disciplinares e mesmo nos órgãos de preservação.

Para Jacquot (2012), a pesquisa sobre a patrimonialização se inscreve em uma geografia social preocupada com as estratégias simbólicas de apropriação do espaço e do tempo, e como legitimação política de sua presença no lugar, reforçando territorialidades particulares.

Interessante observar que a Geografia entrou no debate sobre o patrimônio no momento em que a própria noção de patrimônio cultural estendeu as suas tipologias e as suas escalas cronológica e espacial (Choay, 2001). Este fato, somado às diferentes expressões da mundialização da cultura e da globalização da economia, deram ao patrimônio cultural um novo e importante papel no planejamento do território, seja por meio das políticas de imagem do planejamento urbano ou na valorização de áreas naturais, ambas objetos de políticas e interesses econômicos mediados pelos órgãos de preservação locais, nacionais ou internacionais, como a própria Organização das Nações Unidas para a Educação, a Ciência e a Cultura (UNESCO), sujeito fundamental na nova geopolítica dos patrimônios culturais.

A institucionalização do patrimônio também nos faz rever as nossas tradicionais categorias - territórios do patrimônio, lugar da identidade, paisagens culturais, para citar apenas algumas -, hoje já incorporadas ao processo de patrimonialização, assim como nos força a rever internamente as nossas fronteiras internas (geografia econômica, política, cultural, apenas para citar algumas), ou mesmo criar mais porosidade em nossas fronteiras disciplinares (história, arquitetura, sociologia, antropologia, entre outras) (Veschambre, 2007).

Assim, o processo de patrimonialização se inscreve na trama do planejamento territorial e é orientado por finalidades que vão além da conservação do patrimônio cultural, como será observado nas contribuições dos artigos aqui presentes. Vale a pena frisar que as políticas públicas, os interesses 
econômicos e os conflitos sociais de representação situam as heranças do passado no contexto da produção do presente.

Com este livro pretendemos apresentar diferentes possibilidades de olhar, de modo que o leitor, que agora nos lê, possa percorrer por variadas interpretações das ciências sociais sobre o patrimônio cultural, o turismo e o planejamento territorial, visualizando os campos disciplinares em diálogo. Aqui encontram-se contribuições de autores advindos da Geografia, da Arquitetura, da História e da Sociologia, com grande experiência acadêmica e, também, como Conselheiros ou Profissionais dos órgãos de preservação do patrimônio do Brasil. Além disso, reuniu-se a nós três contribuições de autores estrangeiros: da Argentina, de Portugal e da Itália, nos mesmos campos de atuação.

O livro que agora apresentamos inicia as suas reflexões com a contribuição de Ana Fani Carlos, importante geógrafa da comunidade científica brasileira, e referência nos estudos sobre teoria e método em geografia urbana. Embora os seus principais interesses temáticos não sejam o turismo e o patrimônio cultural, a partir do seu conhecimento sobre a produção e a reprodução do espaço, dedicou o seu olhar para o cruzamento entre estas duas áreas tão presentes nas tendências contemporâneas do planejamento urbano.

Partindo de uma abordagem geográfica de modo a buscar compreender criticamente a espacialidade constitutiva do processo social, toma o patrimônio cultural em sua relação direta com o turismo, na perspectiva econômica do valor de troca, já que, para o turismo, o patrimônio é constituído "como uma particularidade do espaço construída pelo tempo acumulado", e pode ser considerado um valor a ser vendido e consumido no mercado cultural. Em sua hipótese, o patrimônio como representação, tanto da sociedade, do mercado, como do Estado, capta a memória do tempo histórico e a transforma em abstração concreta na circulação do mercado.

Seguindo o seu pensamento, o casamento entre patrimônio cultural e turismo acaba por fortalecer as contradições entre o valor de uso e o valor de troca revelados na produção do espaço. Com o espraiamento das cidades, a raridade do espaço, a necessidade de reestruturação urbana de áreas deterioradas, a reincorporação funcional do patrimônio histórico e arquitetônico do tecido urbano tornou-se uma saída para a reincorporação destas áreas. Embora concorde que "o patrimônio escapa, em seus usos mais profundos, ao uso turístico, já que se situa no conjunto mais amplo da repro- 
dução do espaço (numa articulação de escalas tanto espaciais quanto temporais)", é do patrimônio tempo-espaço tornado mercadoria, do ponto de vista do turismo, que irá tratar. Embora concordemos com Yúdice (2013, p.13), para quem a cultura tornou-se um recurso econômico, mas não no seu simples formato de mercadoria, mas como eixo estruturante de uma nova racionalidade de organização ideológica e epistêmica, como suporte das políticas públicas e dos interesses da iniciativa privada, parece ser difícil negar esta determinação mais hegemônica no processo contemporâneo de valorização do patrimônio cultural urbano.

Mas Fani vai mais longe, desbravando o tempo do avesso para encontrar nas raízes da modernidade o que nos aproxima e nos distancia dela. Flana pela flânerie do tempo perdido para afirmar que, enquanto a destruição do passado promovida pela nova racionalidade urbana, a começar por Haussmann, em Paris, estigmatizou as heranças históricas e as tradições; nós, no presente e com o turismo, espetacularizamos nossas ruínas para serem consumidas como exterioridade - experiência forjada de um cotidiano de pertencimento que não nos pertence. Nesse espetáculo o lugar do patrimônio se confunde entre "o real e o postiço", "entre o recuperado e o autêntico", entre o uso da tradição vivida no cotidiano do lugar, e o mercado de troca de bens simbólicos avaliados externamente.

Assim, segunda hipótese apresentada pela autora, patrimônio e cultura tomados como mercadoria constituem-se fetiches. E é na prática espacial que esse falso encantamento da história tornada presente se substancia como mercadoria.

A segunda contribuição deste livro é de Rafael Winter Ribeiro, geógrafo que trabalhou como Consultor da UNESCO para o Programa de Especialização em Patrimônio do IPHAN (PEP/IPHAN), Pesquisador Associado do Programa de Especialização em Patrimônio PEP/IPHAN, e que traz suas leituras do patrimônio cultural olhando o Rio de Janeiro, particularmente, o Cais do Valongo.

A partir da Geografia há inúmeros subcampos que podem orientar as nossas interpretações do mundo e, aqui, do processo de patrimonialização. Rafael faz da Geografia Política as suas lentes. Preocupado com o contexto da democracia e com as práticas cidadãs, Rafael vai abrindo a cena política do conflito de representações de identidade que instituem o patrimônio e que têm no território a sua base. É com esta preocupação que revê as políticas patrimoniais no Brasil, assim como algumas paisagens cariocas e, especial- 
mente, o Cais do Valongo, com Dossiê aceito em setembro de 2015 para compor a Lista de candidatura a Patrimônio da Humanidade pela UNES$\mathrm{CO}$, aprovado como o $21^{\circ}$ sítio brasileiro inscrito na Lista do Patrimônio Mundial em julho de 2017.

Atento aos discursos que legitimam a prática patrimonial, passa pelo início do século XX, quando a identidade nacional cimentava a trama; pelo importante papel dos discursos dos especialistas do patrimônio; pelos anos 1970, quando o sítio histórico deixa de ser visto apenas como excepcionalidade monumental e obra de arte para tornar-se documento histórico; e pelos anos 1980, quando o processo de redemocratização também chega às práticas patrimoniais - ao menos nos discursos - e a noção de Referência Cultural carregaria em seu bojo uma mudança de paradigma: do patrimônio restrito ao universo dos especialistas ao patrimônio que só teria sentido se fosse um valor construído e atribuído pelo seu próprio grupo social de referência espacial.

Auxiliado por Fonseca (1998, p.33), ele aponta que a mudança naquele momento não se referia, exclusivamente, aos bens patrimoniais, mas a uma nova forma de compreender a natureza de valoração do patrimônio cultural, que acabaria por instituir um instrumento para Registro do Patrimônio Imaterial e absorver sujeitos sociais que, até então, estavam marginalizados do processo de patrimonialização, tanto da seleção quanto de seu desfrute.

Além disso, segundo Winter, a partir dos anos 1970 a prática patrimonialista perde o seu medo da modernização e passa a incluir em seu repertório os sujeitos em suas práticas culturais vivas, incorporando as mudanças sociais.

Para argumentar empiricamente com a sua reflexão conceitual, chama dois casos específicos para análise: a inscrição de partes da cidade do Rio de Janeiro a candidatura a Patrimônio Mundial pela UNESCO, eleita na tipologia de Paisagem Cultural, em 2012, mas ainda sem a sua gestão implementada; e o processo do Cais do Valongo, na Zona Portuária.

Com estes dois exemplos o autor nos apresenta, segundo a sua interpretação, dois casos diferenciados. O primeiro, das Paisagens Cariocas: entre a montanha e o mar, informa sobre um processo que ocorreu de cima para baixo, pelo olhar dos especialistas e sem a participação ou consulta dos diversos representantes sociais; o segundo, do Cais do Valongo, como um processo que acolheu e respeitou o diálogo e a participação social, o que institui os lugares de memória. 
Só o tempo dirá se a força do lugar resistirá ao parque temático que, nestes casos, vive do discurso para um herói inventado de modo a encobrir a identidade daquele que, durante tanto tempo na história, foi estigmatizado.

Paulo César Garcez Marins, historiador e Professor do Museu Paulista da Universidade de São Paulo, trás uma necessária reflexão sobre os significados que estruturam a Lista do Patrimônio Mundial no Brasil e o que estes revelam de nossa própria trajetória de preservação.

Após um longo período de "hipervalorização do período colonial", mesmo o reconhecimento de Brasília como patrimônio cultural da humanidade, em 1987, ainda estava ligado a forte representação de modernistas, tais como Oscar Niemeyer, Lúcio Costa e Burle Marx, expoentes que tiveram um papel fundamental para o Iphan na preservação da memória colonial. Para Paulo Garcez, essa abertura para a preservação da arquitetura modernista também revelou "imensos compromissos semânticos entre os modernistas e a preservação de sua própria memória”, e sem terem conseguido, ainda, equilibrar esta balança ${ }^{1}$. A UNESCO ainda nos reflete, majoritariamente, como patrimônio colonial, primado também incontornável para o Iphan que concentrou em Minas Gerais, Rio de Janeiro, Bahia e Pernambuco grande parte dos conjuntos e edificações tombadas pelo Órgão.

E sobre esse primado Paulo vai relatando caso a caso, destacando que, ainda que alguns sítios tivessem sofrido inúmeras transformações, exclusões ou acréscimos, particularmente nos séculos XIX e XX, a busca por uma narrativa de conjuntos homogêneos preservados dos séculos XVI, XVII ou XVIII construiu esta realidade.

O patrimônio mundial natural também é fracamente representado pela Lista da UNESCO, o que, provavelmente, revela a nossa natureza partida entre as administrações do meio ambiente e as do patrimônio natural e cultural. A inclusão, em 2012, de "paisagens cariocas" como Paisagem Cultural, na Lista do Patrimônio Mundial, parece revelar as contradições levantadas por Paulo Garcez.

Do patrimônio imaterial à expansão "do estoque" de bens materiais tombados, Paulo Garcez vai construindo uma dialética entre a ampliação da patrimonialização visível no território nacional e as sombras não referenda-

1. Vale destacar que em 07 de julho de 2017 o Iphan declarou 27 obras de Oscar Niemeyer, localizadas em Brasília, Rio de Janeiro e São Paulo, como Patrimônio Histórico Nacional. 
das pelo processo institucional, sejam nacionais ou mundiais. De qualquer forma, para além do patrimônio colonial, parece estarmos vivendo em um período que aponta para a possibilidade de representação de um país mais heterogêneo - é com esta aposta que o autor finaliza o seu artigo.

Lia Motta, arquiteta, nome conhecido da preservação patrimonial do Brasil, técnica do Iphan há vários anos, Coordenadora Geral de Pesquisa, Documentação e Referência do IPHAN (COPEDOC) e do Programa de Mestrado Profissional do órgão, nos brinda com este artigo: $O$ patrimônio urbanístico e seus usos sociais.

Colocando a Constituição Federal de 1988 como marco de partida, propõe-se a discutir sobre a superação da hegemonia da construção do patrimônio nacional, pautada nos valores estético-estilísticos da arquitetura colonial e nos bens de caráter excepcional, em relação às referências culturais diferenciadas e presentes na sociedade brasileira, de modo a construir uma memória social a partir deste marco.

Segundo as suas palavras: "Apenas na lida com o patrimônio de natureza imaterial que a referência cultural vem norteando os trabalhos de forma mais ampla”. Com esta constatação, nos diz da urgente tarefa de refletir sobre os usos sociais dos bens culturais, e ousa colocar luz ao patrimônio urbano do Complexo da Maré, no Rio de Janeiro, "experiência pioneira de construção de memórias coletivas pelos moradores, como modo de dignificar o lugar e criar um sentimento de autoestima e pertencimento a história da cidade".

Antes da empiria, costura a teoria e as narrativas patrimoniais, passando pelas várias formas de interpretarmos a memória, pela construção da noção de Referência Cultural no Iphan, à participação das comunidades nos processos de preservação.

Atenta à urgência diante do crescente interesse turístico pelo patrimônio e da criação do patrimônio globalizado que podem assolar a memória das cidades e das próprias populações que vivem em uma situação marginal em relação a este processo hegemônico, vai se inspirar em uma experiência de Aloísio Magalhães, nos anos 1980, que encontrou patrimônio cultural tendo por guia uma moradora em uma pequena cidade de Pernambuco, Triunfo, em uma prática social cotidiana que despertou a sua compreensão para a representatividade de, simplesmente, "uma forma de vida". $\mathrm{Ou}$ seja, considerando que Magalhães era então Presidente do Iphan, estava instalada a forma de viver dos moradores como patrimônio cultural - uma 
ruptura profunda com os parâmetros anteriores. Segundo Lia, o processo de atribuição de valor "ao sítio urbano de Triunfo a partir da apreensão da moradora” levou à consagração do conceito de Referência Cultural na Constituição de 1988 e, como consequência do amadurecimento da questão, ao Programa Nacional do Patrimônio Imaterial (PNPI), em 2000.

Apesar das novas concepções e instrumentos colocados, Lia Motta afirma que pouco se fez no período, sendo ainda mais representativo do órgão de preservação o patrimônio de "pedra e cal". Mas é desta nova perspectiva patrimonial que coloca os sujeitos sociais e suas referências culturais como protagonistas em diálogo com os sujeitos institucionais do saber técnico que Lia quer falar.

No Complexo da Maré identifica a convivência de várias Marés, cada uma oriunda de tempos e memórias históricas diversas. A cidade tradicional, a dos conjuntos projetados e monofuncionais e as vias de circulação. Os detalhes desta história os leitores terão em seu artigo que finaliza com a defesa da dignificação da história destes sujeitos e lugares por tanto tempo esquecidos da seleção patrimonial.

Simone Scifoni, geógrafa que também atuou como técnica do Conselho de Defesa do Patrimônio Histórico, Arqueológico, Artístico e Turístico do Estado de São Paulo (CONDEPHAAT) e do IPHAN, pesquisou o patrimônio natural da Mata Atlântica em seu doutorado, e tem se dedicado ao patrimônio urbano, parte de uma crítica à gestão urbana de característica empresarial, como afirma, "ao modo de pensar e fazer política de patrimônio no Brasil", e questiona "a natureza desigual do tratamento dado aos patrimônios e o universo também desigual da produção da cultura no Brasil". É deste lugar que volta os olhos para o patrimônio dos grupos sociais subalternos, especialmente aquele associado ao operariado fabril da metrópole paulistana, colocando em destaque os seus modos de vida e o seu patrimônio material, muitas vezes esquecidos na hierarquia de capitais culturais e em face de um patrimônio industrial mais valorizado, como as grandes edificações e infraestruturas técnicas, inclusive a partir dos discursos da UNESCO, que dão aos trabalhadores - sujeitos desta memória social - um papel secundário.

Como já demonstrado nos artigos de Rafael Winter Ribeiro, Paulo César Garcez Marins e Lia Motta, reafirma a crítica às ideologias e ao reducionismo espacial e tipológico levados a cabo na fase heroica de construção do patrimônio nacional. Também reforça o papel da Constituição Federal de 
1988, embora a considere "essencialmente discricionária", criticando a sua real utilização na prática política em relação a efetiva inclusão cidadã da "colaboração da comunidade", conforme escrito na própria Constituição. Nesse sentido questiona: "Até que ponto houve mudança?".

Recuperando o conceito de modelo globalizado, de Motta (2000), critica a forma de intervenção urbana das políticas patrimoniais a partir dos anos 1990, e a sua associação aos modelos urbanos do planejamento estratégico de caráter empresarial, inspirado em Barcelona, a partir de 2000, que selecionou apenas as edificações arquitetônicas de grande visibilidade e retorno para uma refuncionalização elitista.

Segundo a autora, os movimentos sociais de luta pela preservação são reflexos da desigualdade nas políticas patrimoniais. Discordando de que o processo de patrimonialização que ocorreu na Europa tenha se dado no Brasil, como afirmam vários autores, afirma que "No Brasil há um grande passivo patrimonial a ser identificado, protegido e valorizado", o que justifica ainda a expansão da patrimonialização pelo Iphan. Para ela, aqui, não há uma "indústria ou inflação patrimonial", sobretudo porque ainda temos grande parte de nosso acervo patrimonial deteriorado ou em péssimas condições de conservação, ainda que as políticas públicas que estimularam a revalorização imobiliária das áreas centrais tenham requalificado e dado visibilidade a estas áreas.

Mas aqueles bens imóveis que não se enquadram no atrativo consumo cultural, segundo ela, continuam abandonados, e assim situa alguns exemplos na cidade de São Paulo. Segundo ela, "Somente a partir de uma inversão de olhar é possível compreender os espaços fabris e seus equipamentos para além do viés da técnica, dos meios de produção e do capital", e então propõe um "inventário dos lugares de memória operária", onde seriam incluídos "os lugares de trabalho, lugares de luta, lugares de moradia e da vida cotidiana”.

No sentido inverso, o artigo de Paulo Peixoto, em tom bastante crítico, analisa o processo mundial de patrimonialização em sua negociação política, em seus discursos hegemônicos, especializados e pouco democráticos e, em grande medida, orientados pelas estratégias dos interesses do setor turístico e do consumo cultural.

Entre as narrativas retóricas necessárias ao processo de patrimonialização, aponta os processos de indicação da UNESCO e os conceitos de sustentabilidade e participação. Tomando como referência a França, vira do avesso 
tal processo e avalia o lugar da despatrimonialização, ou, como denomina, da eutanásia do patrimônio. Afinal, o que é patrimônio é relativo ao período histórico, às suas ideologias, imaginários, interesses e narrativas. Paulo Peixoto nos provoca a pensar a essencialização reducionista da "fúria patrimonialista".

Citando Dresden, no Vale do rio Elba, na Alemanha, mostra como estes discursos podem estar em desacordo com as populações do lugar patrimonializado, ou mesmo, como em muitos casos, inclusive no Brasil, algumas populações ignoram completamente o processo de indicação da UNESCO sobre o sítio no qual simplesmente vivem.

Então, o patrimônio representado pelo lugar seria mais importante do que o patrimônio lugar que se torna mundial? Parece que estamos vivendo um momento de ruptura desse longo processo de patrimonialização. Quem sabe estejamos mesmo abandonando as bases da modernidade junto com a sua esquizofrenia, como nos foi apresentada por David Harvey (1992).

Rodolfo Bertoncello, geógrafo do CONICET e da Universidade de Buenos Aires (UBA), Argentina, preocupa-se mais de perto com as práticas sociais, a mobilidade e as condições tecnológicas e organizacionais do turismo. Faz um zoom na expansão do turismo cultural e chega na valorização contemporânea do patrimônio cultural.

Relembrando Mac Cannell (2001), coloca em questão a autenticidade dos bens culturais valorizados pelo turismo, assim como a experiência turística que ganhou força como produto nesta associação entre turismo e cultura.

Atualmente, praticamente todas as manifestações culturais são de interesse turístico, afirma, sendo o diferencial territorial uma matéria prima que estrutura o setor, o que inflaciona a produção de lugares turísticos. Por outro lado, é preciso refletir que nos destinos turísticos estão sujeitos sociais concretos e que esta produção só ocorre a partir de uma organização política, dos interesses sociais e econômicos, e não da simples vocação do lugar. Deste modo, o autor passa a investigar as estratégias destas formas de organização - "As manifestações culturais que os turistas observam e desfrutam são o resultado de tudo isso". E o recurso ao patrimônio cultural como atrativo torna-se, assim, uma dessas estratégias que coloca as cidades como importantes destinos do turismo cultural.

Então, como já apontado por outros autores para o caso brasileiro, os processos de renovação, refuncionalização ou gentrificação urbanas têm pre- 
parado cidades em todo o mundo para a visitação turística. Como afirma Rodolfo Bertoncello, "A cidade convertida em um cenário para ser visto e admirado pelos turistas vai incluindo cada vez mais fragmentos de sua totalidade cotidiana, garantindo a oferta de novos produtos e a manutenção de sua atratividade", e fazendo da convivência dos processos de uma globalização homogeneizante e de uma diferenciação cultural o seu objeto mais precioso.

Marina Faccioli, geógrafa da Universidade de Pisa, na Itália, e especialista em estudos urbanos e regionais, nos fala do enfraquecimento das relações de pertencimento e das configurações locais do Planalto da Sila - ambientais, culturais e em relação ao trabalho - devido a agregação territorial ocorrida na Sila, em toda a região da Calábria, e mesmo em todo Mezzogiorno.

Lembrando o termo "vocação" e uma certa "individualidade original", trata desta história longa de parte da Europa que, rica em florestas, constituiu uma cultura sobre a prática econômica da madeira e das atividades de pastoreio. Lembrando as paisagens culturais, vai nos apresentando esta cultura tradicional, sua história natural, suas relações com o trabalho rural, e o desmembramento de grandes empresas pastoris e de cereais. A repartição desta região em modernos municípios que acolheram suas heranças culturais em declínio em uma nova forma de regionalização afetou o planalto agrícola, caracterizado agora por uma organização moderna e pela inclusão de circuitos culturais para estas rugosidades do campo.

Segundo Marina, esta nova configuração que caracteriza Sila, estimulada pela demanda diversificada do consumo, trouxe "charme e originalidade" a uma área. A criação de um Parque Nacional onde se valoriza o uso tradicional da terra, suas dinâmicas de ocupação tradicionais, a recuperação da área e suas condições ambientais, com o uso de novas tecnologias, representou o "renascimento" nas novas dinâmicas da região.

Assim, "no contexto da renovação dos processos e formas de uso do solo de Sila", a recuperação do ambiente natural, a modernização agrícola com a permanência de heranças culturais tradicionais, e o papel do turismo na recuperação da região foi fundamental para a renovação de seu potencial competitivo e produtivo.

Após avaliar os processos de gestão, a autora enfatiza o papel do Parque Nacional como sujeito de integração territorial, em um contexto de diálogo com as cidades do entorno e sua estrutura regional. 
Assim, em outro contexto territorial, na Europa, em outra Geografia, a italiana, temos como contribuição este elogio a um Parque Nacional e ao seu papel na recuperação ambiental, na modernização agrícola dos usos, na manutenção das tradições e na inserção de uma área que estava em declínio econômico diante das novas redes globais do consumo do território.

Davis Gruber Sansolo, geógrafo atuante nas lidas do meio ambiente, nos traz um caso no qual esteve envolvido para apresentar suas considerações sobre o patrimônio natural comunitário em Silves, no Amazonas (AM), onde, segundo ele, "nasceu uma das primeiras iniciativas de turismo de base comunitária no Brasil". Situando a sua interpretação de lugar, e aproximando o patrimônio natural ao turismo, nos apresenta as conquistas e os conflitos da população local no momento em que a Associação de Silves para a Proteção do Ambiental e Cultural (ASPAC) propôs à população local o manejo no uso dos lagos ali existentes, e em que foi criada a Cooperativa de Turismo (COOPTUR), em 2005, para a gestão do turismo comunitário da ASPAC.

Os ganhos e conflitos daí provenientes o fez afirmar a sua hipótese: embora a população tenha fortalecido os seus laços de pertencimento ao lugar, após a ameaça colocada pela pesca profissional, a articulação dos ribeirinhos em torno da ASPAC e da COOPTUR colocou em conflito a lógica tradicional de manejo do patrimônio natural com a gestão do saber técnico para o patrimônio natural.

Assim, com contribuições variadas, mais consonantes do que dissonantes, os artigos que compõem este livro constituem um rico e atualizado acervo para todos aqueles que buscam desenvolver reflexões críticas, realizar pesquisas comprometidas com a realidade contemporânea e atuar em trabalhos especializados no campo patrimonial, do turismo e das ciências humanas. 
Di Meo, Guy. 1994. "Patrimoine et territoire, une parenté conceptuelle". In: Espaces et Sociétes, 1994/4 ( $\left.\mathrm{n}^{\circ} 78\right)$.

FONSECA, M.C.L. "A noção de referência cultural nos trabalhos de inventário. In: MOTTA, Lia; SILVA, M.B.R. (Orgs) Inventários de identificação. Iphan:Rio de Janeiro, 1998.

GRAVARI-BARBAS, Maria et Jacquot, Sébastien. 2014. Patrimoine mondial et développement: au défi du tourisme durable. Collection Nouveaux patrimoines, Editions PUQ (Presses de l'Université du Québec), 296 pg.

HARVEY, David. 1992. A condição pós-moderna - uma pesquisa sobre as origens da mudançacultural, Edições Loyola, São Paulo, S.P.

HERTZOG, Anne. 2011. «Les géographes et le patrimoine», EchoGéo [En Ligne] : URL: http ://echogeo.revues.org/12840 : DOI : 10.4000/echogeo.12840.

LAZZAROTTI, Olivier. 2011. Patrimoine et tourisme: Histoires, lieux, acteurs, enjeux. Éditions Belin (Tourisme), Paris, France. (302pg).

2000. "Patrimoine et tourisme: un couple de la mondialisation". Mappemonde 57 (1), 16p.

MAC CANNELL, Dean. 2001. “Tourist Agency”, In: Tourist Studies. 1(1), 23-37.

MOTTA, Lia. "A apropriação do patrimônio urbano: do estético-estilístico nacional ao consumo visual global. In: ARANTES, A.A. (Org). O espaço da diferença. Campinas: Papirus, 2000, pp. 257-287.

PAES, M.T.D. e OLIVEIRA, M.R.S. 2009. Geografia, turismo e patrimônio cultural (229 pg.), Editora Annablume \& Fapesp, SP.

2015 "As cidades coloniais brasileiras - ideologias espaciais, valores histórico, urbanístico e cultural” (pp.41-68). In: GEOgrafhia, Vol.17, N.33, Universidade Federal Fluminense (UFF), Rio de Janeiro.

VESCHAMBRE, Vincent. 2007. "Patrimoine: un objet révélateur des évolutions de la géographie et de sa place dans les sciences sociales" (361-381). Annales de géographie, 2007/4 (n 656).

YÚDICE, George. 2013. A conveniência da cultura - usos da cultura na era global. Editora UFMG/Humanitas, Belo Horizonte, MG. 